\title{
La función del editor en el libro del siglo XVI ${ }^{*}$
}

\author{
Manuel José PEDRAZA GRACIA \\ (Universidad de Zaragoza)
}

\section{Resumen}

La edición ofrece un panorama complejo en el que solo se ha profundizado, en la mayoría de las ocasiones, desde una perspectiva teórica. El mínimo análisis de los múltiples documentos referidos a este problema ofrece una casuística compleja que requiere una clasificación. Esa documentación es la que sirve a este trabajo para analizar, a partir de las distintas responsabilidades y facetas de intervención acordadas en ella, la intervención del editor en el libro. Para ello se ha contado con un importante corpus de contratos editoriales obtenidos de los archivos de los protocolos notariales españoles

Palabras clave: Edición; España. Siglo XVI; Impresor; Librero.

\section{The role of the publisher in the book of the sixteenth century}

\section{Abstract}

Edition offers a complex picture that has only been reviewed, in most cases, from a theoretical perspective. The analysis of multiple documents referred to this problem offers such a complex casuistry that a classification is required. By studying responsibilities and intervention aspects agreed in documents, this works examines the intervention of editors in the book. To

* Trabajo realizado con el apoyo del Proyecto de la Secretaría de Estado de Investigación, Desarrollo e Innovación del Ministerio de Economía y Competitividad HAR 2011-23196. 
do so, this work is based on the analysis of a substantial corpus of publishing contracts obtained from Spanish archives of notarial protocols.

Keywords: Edition; Spain; 16th Century; Printer; Bookseller.

En los estudios sobre el libro, desde el siglo XVIII hasta la actualidad se ha llegado a un conocimiento bastante profundo sobre las imprentas porque se le ha dado al estudio de los impresores la máxima importancia y, aunque los investigadores son conscientes de las numerosas lagunas que aún existen sobre ese conocimiento. Por el contrario, prácticamente se desconoce casi todo sobre los editores y su función en la elaboración del producto bibliográfico; y, de forma similar, son también importantes las lagunas que existen en torno a los libreros y la distribución del impreso.

En este trabajo se pretende ofrecer una panorámica de la participación del editor en el conjunto de actos que conducen desde el original al libro impreso en la librería, forzosamente incompleta, ya que la ausencia de información al respecto y la casuística, que puede ser muy variada, lo hace inevitable.

\section{La figura del editor}

La figura del editor es con seguridad la que menos interés ha despertado entre los investigadores y no se debe aceptar sin más que cuando una investigación habla de edición lo hace en efecto, sino que, más bien, se refiere a los procesos de fabricación y distribución. En cualquiera de los casos, se trata, sin lugar a dudas, de una figura principal en estos procesos o, mejor dicho, su función es esencial, lo que no implica que otros agentes de la producción del libro puedan llevarla a cabo. ${ }^{1}$ Quizás la ausencia de la percepción de la importancia de la figura del editor esté justificada porque la función del impresor es muy evidente y, con algunas salvedades, lo es también la de librero; mientras que la del editor en la época ni siquiera está definida como una labor diferenciada al respeto de la producción del libro y, por consiguiente, no está contemplada con la misma perspectiva en la legislación contemporánea.

\footnotetext{
${ }^{1}$ No quiere decir que un autor pueda también realizar la función de edición y lo mismo ocurre con los libreros, los mercaderes de libros o los papeleros. Artesanos y comerciantes dedicados a esas labores han sido encontrados en los restos documentales conservados como editores cumpliendo además de la función que les identifica en la época la de edición, mucho más difuminada.
}

Titivillus, ISSN 2387-0915, ISSN-e 2603-9966, 1 (2015), pp. 211-226 
Si se analizan las funciones de cada uno de los agentes de la producción del libro se obtendrá una panorámica más efectiva. En las imprentas se imprimen pliegos de papel y con los pliegos se conforman los cuadernos, pero no se elaboran libros, como objeto único no divisible. Es cierto que el conjunto de cuadernos, llamado en la época cuerpo, pieza o ejemplar, va a permitir la confección del libro, pero no es el lugar en el que crea el libro. En las librerías, de ahí su nombre, se toman los cuerpos (conjunto de objetos diferentes entre sî) elaborados en la imprenta y con ellos se forma un objeto único, el libro o volumen. Es cierto que en la librería se dispone de libros (ya encuadernados), cuerpos o piezas para encuadernar según el gusto estético y las posibilidades económicas del comprador y mandante (una vez que los haya adquirido), libros blancos (para escribir las actas de las instituciones o las cuentas del tendero...), plumas, papel... Pero también se confunde al librero con el mercader de libros, figura poco estudiada que, en buena parte, podría coincidir con el distribuidor actual. El mercader de libros adquiere del editor ediciones completas o parte de ellas que distribuirá en lugares diferentes proveyendo a los libreros y feriantes, (no directamente a los lectores). ${ }^{2}$ Es necesario hacer la salvedad de que en el Renacimiento y la Edad Moderna, en tanto no hay gremios que defienden los intereses de los profesionales, estos límites son verdaderamente difusos, y no es raro el impresor que posee una librería o que actúa como mercader de libros, propios y ajenos; y tampoco es raro encontrar mercaderes de libros que poseen librería. Por consiguiente, tampoco será infrecuente que actúen en muchas ocasiones como editores.

Entonces, qué hace el editor. Desde una perspectiva funcional se podría decir que el editor es el que paga los costes de la elaboración de la impresión, pero hay algo más importante que la financiación de la edición: tomar la decisión de que una obra vea la luz por primera vez o sea editada de nuevo, es decir que sea publicada. ${ }^{3}$ Por consiguiente, el editor se coloca en el primer lugar de la cadena. El editor decide publicar una obra y esta decisión no responde a una necesidad o interés cultural, sino comercial; por consiguiente no se puede identificar al editor con un mecenas que se dedica al desarrollo de la cultura de sus contemporáneos, ya que detrás de su actuación existe un interés principalmente económico y, en su defecto, fines propagandísticos o

\footnotetext{
${ }^{2}$ Cf. Manuel José Pedraza Gracia, «El control de la distribución del libro en Zaragoza y la defensa de los privilegios de los libreros en los siglos XVI y XVII: el gremio de libreros contra Juan Baube», Pliegos de bibliofilia, 28 (2004), pp. 51-60.

${ }^{3}$ Sobre la edición of. Jaime MOLL RoQueTAS, «Problemas bibliográficos del libro del Siglo de Oro», Boletín de la Real Academia, 59 (1979), pp. 49-107; y «El impresor, el editor y el librero», en Historia de la edición y la lectura en España, 1475-1914, bajo la dirección de Víctor Infantes, François Lopez, Jean François Botrel, Madrid, Fundación Germán Sánchez Ruipérez, 2003, pp. 77-84.
} 
de utilidad política. ${ }^{4}$ No es extraño que los principales agentes de la edición sean los profesionales más próximos a todos estos procesos, autores, impresores, libreros y, también los creadores de la principal materia prima, los papeleros, puesto que son los que mejor conocen los entresijos del mercado por estar más próximos a él y por ser los que mejor calibran la rentabilidad del negocio.

Esta actividad, como toda actividad de carácter comercial y económica parte de un contrato entre el editor ${ }^{5} \mathrm{y}$ un empresario, cuya empresa se dedica a fabricar el objeto; y una vez fabricados los cuadernos, es preciso proceder a su distribución. El beneficio puede obtenerse mediante la venta conjunta de la edición al mayor o a la venta en bloques o por unidades, en algunas ocasiones con el valor añadido de la encuadernación.

Los propios libros no ofrecen demasiados datos sobre los editores puesto que la función no está identificada en la época como tal. En la mayoría de las ocasiones no aparecen simplemente porque no reportaría información válida en la época. Cuando figuran, los datos del editor figuran muy frecuentemente como indicación de financiación relacionada, los más de los casos, con la propaganda del lugar en el que se puede adquirir, por lo que cabría pensar que la labor de edición recaía de manera muy principal en libreros que mencionan en los pies de imprenta el lugar en el que se puede adquirir el libro. Y no suele ir más allá.

\section{Los contratos de impresión}

Se puede encontrar, sin embargo, una información sobre los editores y con una mayor calidad de datos en la documentación comercial, puesto que, como se ha dicho, en el fondo se trata de un negocio. ${ }^{6}$ Los contratos aportan

${ }^{4}$ Cf. Manuel José PEDRAZA GRACIA, «Mecenazgo y edición en la primera mitad del siglo
XVI, El "Florindo" de Fernando Basurto (Zaragoza, Pedro Hardouin, 1530)», Rilce, 32, 1
(2016), pp. 229-247.
${ }^{5}$ En muchas ocasiones el editor había comprado previamente el privilegio de impresión al
autor. En 1588 el librero adquirió el privilegio de impresión de Pedro de Ribadeneyra para
imprimir su Historia eclesiástica del cisma de Inglaterra. Vid. Cristóbal PÉREZ PASTOR,
Bibliografía Madrileña ó descripción de las obras impresas en Madrid... Parte tercera (1621-1625),
Madrid, Tipografía de la "Revista de Archivos, Bibliotecas y Museos", 1907, p. 460.
También se puede dar el caso de que el privilegio se ceda a cambio de ejemplares de la
edición una vez acabada. De esta manera procedió fray Juan López al ceder al mercader
Juan Boyer el privilegio de su Nuestra Señora del Rosario a cambio de 100 ejemplares
impresos. Cristóbal PÉREZ PASTOR, La imprenta en Medina del Campo, Madrid,
Establecimiento Tipográfico "Sucesores de Rivadeneyra", 1895, pp. 297-8.
${ }^{6}$ En los archivos notariales se encuentra la documentación de carácter privada y entre esta
documentación resultado del acuerdo entre particulares o de particulares e instituciones se

Titivillus, ISSN 2387-0915, ISSN-e 2603-9966, 1 (2015), pp. 211-226 
información muy variada. Pero esta información no hace referencia a todos los libros que se imprimieron, porque ni todos fueron editados previo contrato, ni todos lo requirieron. Es, sobre todo, es muy frecuente en los primeros tiempos que el impresor sea también el editor de sus producciones. Por esta causa, se pueden encontrar muchas obras de las que, con frecuencia, se dice que carecen de editor o para las que no se puede hablar propiamente de editores. Quizás sería más apropiado decir que poseen un editor-impresor o un impresor que edita las obras que imprime, ya que, a pesar de quedar patente la función de impresor, no se omiten indicaciones que dejan perfectamente especificadas las dos actuaciones en sus producciones bibliográficas: ser responsables de su impresión, haberse impreso "en su casa", y que también han llevado a cabo esa impresión a sus "expensas" o "costas". Obviamente, si el impresor se lanzaba al negocio de llevar a cabo la impresión de una edición concreta podía realizarla cuando le placiese, con los recursos técnicos que estimase oportuno, en los tiempos que conviniesen al negocio y sin contrato alguno que le condicionase; pero arriesgando su capital en el supuesto de que la obra o la edición no se pudiese vender. Pero si la iniciativa parte de un editor se contrata una obra o servicio, la impresión de un libro, sobre el que la sociedad impresora no tiene ningún derecho (ni sobre el original ni sobre la producción). Existe una situación intermedia según la cual el impresor debe recuperar la inversión realizada mediante la libre disposición de parte de la edición. ${ }^{7}$ De la misma manera se suele pagar también al autor. ${ }^{8}$ Solamente el segundo y tercero de los casos pueden dejar algún rastro documental por lo que existen un número importante de contratos que

pueden encontrar los contratos para editar libros, entre otros muchos tipos de actuaciones realizadas en torno al mundo del libro.

${ }^{7}$ En el contrato realizado entre el Obispo de Lérida y Jorge Coci el día 1 de abril de 1524 para imprimir 300 Misales en folio de la diócesis de Lérida se acuerda que al editor se le entregarán 200 de los ejemplares impresos y el impresor se quedará con los 100 restantes. Inédito. Archivo Histórico de Protocolos De Zaragoza (A.H.P.N.Z.), Protocolo de Luis Sora, 1524, f. 115 y cuaderno sin foliar. Sin embargo, ocurre lo contrario en el contrato de 1547 acordado entre el escribano Gaspar de Tejada y Bartolomé de Nájera para imprimir el Libro de títulos y cartas mensajeras, en el que el impresor se queda las dos terceras partes de la edición de 700 ejemplares y el autor-editor la restante. Vid. Manuel ABIZANDA y BRoto, Documentos para la historia artística y literaria de Aragón procedentes del Archivo de Protocolos de Zaragoza, 3 vols., Zaragoza, La Editorial, 1915-1932, vol. 1, pp. 33940, y, posteriormente en Ângel SAN VICENTE PINO, Apuntes sobre libreros, impresores y libros localizados en Zaragoza entre 1545 y 1599. II, Los impresores, Zaragoza, Gobierno de Aragón, 2003, doc. 6 .

${ }^{8}$ El 7 de octubre de 1572 Juan Díaz contrata a René Rabut para imprimir la Descripcion general de Africa con todos los hechos entre moros y christianos entre los propios moros de Luis Mármol; el autor obtiene 50 ejemplares del libro. Vid. José María de la OBRA SIERRA, María José OSORIO PÉrez, María Amparo MORENO TRUjILlo, «El mercado del libro en Granada en el siglo XVI», en José Antonio Cordón García, et al., La imprenta en Granada, Granada, Universidad de Granada, 1997, pp. 43-71; p. 63. 
pueden dar luz sobre los editores y su función, algunos de los cuales son la fuente en la que se basa este trabajo.

Estos contratos aportan información de muy diverso tipo. En general, el editor contrata al impresor para imprimir una determinada obra partiendo de un original impreso o no. $\mathrm{Y}$ para ello se debe llegar a un acuerdo entre las partes sobre muy diversos aspectos que, una vez escrito, se sancionaba ante un notario. Estos contratos lógicamente tratan aspectos esenciales económicos y jurídicos.

Los aspectos de tipo económico principales eran el número exacto de unidades, ejemplares, que se debían imprimir (aunque posee una connotación técnica), ${ }^{9}$ el precio por cuerpo o ejemplar (más raramente), ${ }^{10}$ por pliego impreso (todos los pliegos impresos con las mismas formas), ${ }^{11}$ por resma (que es lo más frecuente $)^{12}$ o por jornada de trabajo ${ }^{13}$ o semana de trabajo, ${ }^{14}$ la existencia de ejemplares de cortesía, ${ }^{15}$ el tiempo máximo en el que se debía

\footnotetext{
${ }^{9}$ El rango es amplísimo ya que va desde el centenar hasta unas decenas de miles de ejemplares, aunque predominan las tiradas de $1000 \mathrm{y}$, especialmente, las de 1500 ejemplares, lo que coincidiría con la jornada castellana que siguen como jornada laboral, de los tiradores y batidores: esto es, 1500 pliegos impresos diarios (blanco y retiración).

${ }^{10} \mathrm{El} 8$ de enero de 1535 Lope Ruiz de Contreras contrata a Jorge Coci para imprimir Misales para el obispado de Urgel pagándole 24 sueldos la pieza. Inédito. A.H.P.N.Z., Protocolo de Juan Arruego 1535, cuaderno numerado con el f. 19.

11 En 1553 el Obispo de Palencia contrata la impresión de los Manuales del obispado pagando a 4 maravedíes el pliego. Vid. PÉrez PASTOR, La imprenta en Medina del Campo, pp. 124-5.

12 Juan Muñoz pacta con Francisco Sánchez la impresión de su Práctica de procuradores el 9 de mayo de 1573 pagando por cada resma impresa 16 reales. Vid. PÉrez PASTOR, Bibliografía Madrileña ó descripción de las obras impresas en Madrid... Parte tercera (1621-1625), p. 434.

${ }^{13}$ En el contrato realizado entre Juan Díaz y René Rabut para imprimir la Descripción general de Africa con todos los hechos entre moros y christianos... de Luis Mármol el 7 de octubre de 1572 así se especifica. Vid. Obra Sierra, Osorio PÉrez, Moreno TrujILlo, «El mercado del libro en Granada en el siglo XVI», p. 63.

${ }^{14}$ Fray Cristóbal de Fonseca contrata con Miguel Serrano el 15 de mayo de 1602 la impresión de su Milagros de Christo, pagando 140 reales cada semana mientras dure la impresión. PÉREZ PASTOR, Bibliografía Madrileña ó descripción de las obras impresas en Madrid... Parte tercera (1621-1625), p. 499

15 Cristóbal de Arroyuelo contrató a Jorge Coci el 23 de marzo de 1506 para imprimir un Breviario de la diócesis de Burgos del que se entregan 20 ejemplares de gracia sobre lo acordado como tirada. Vid. ABIZANDA Y BROTO, Documentos para la historia artística y literaria de Aragón procedentes del Archivo de Protocolos de Zaragoza, vol. 1, p. 321. También, Manuel José Pedraza Gracia, Documentos para el estudio del libro en Zaragoza, 1501-1521, Zaragoza, Centro de Documentación de Bibliografía Aragonesa, 1993, doc. 377.
}

Titivillus, ISSN 2387-0915, ISSN-e 2603-9966, 1 (2015), pp. 211-226 
concluir la producción, lo que se puede establecer de forma directa ${ }^{16}$ o mediante el acuerdo sobre el ritmo de producción (lo que suele establecerse en un pliego diario por prensa $)^{17}$ y el lugar en el que debían ser entregados... ${ }^{18}$ También se localizan algunas claúsulas muy excepcionales como las que obligan a adelantar una cantidad para llevar a cabo la adquisición de elementos esenciales para la impresión. ${ }^{19}$ Los editores que no tienen una relación profesional directa, o de otro tipo, con el libro o la obra, suelen centrar su interés en estos aspectos. Son, sobre todo, los que se reconocen profesionalmente en la documentación como mercaderes. Estos consideran la edición de libros como otro negocio, uno más en los que reinvertir su capital y de los que pueden proporcionarle beneficios. El libro, como producto creado mecánicamente, es una mercancía que se puede convertir en dinero. Desde esta perspectiva se puede comprender que el beneficio es mayor si se interviene desde el momento de la producción que si se interviene meramente como intermediario (de esta manera, se maximiza el beneficio). Como especialistas en el mundo de los negocios, los mercaderes, cuando intervienen en el mundo del libro como editores, ponen especial atención en los aspectos económicos, reservando los aspectos técnicos para los profesionales especializados, los impresores.

Los aspectos fundamentales de tipo jurídico son quizás los principales ya que se refieren a la identificación de las personas que participan en el pacto:

${ }^{16}$ Fray Juan del Espinar contrató el 3 de noviembre de 1575 con el impresor Juan de la Plaza la edición de 2.500 ejemplares de los Calendarios perpetuos en $4^{\circ}$ de los que se entregará la primera jornada el día de Pentecostés del año siguiente al del contrato. Cristóbal PÉREZ PASTOR, «Impresores y libreros de Madrid: documentos referentes a ellos», en Noticias y documentos relativos a la Historia y Literatura Españolas, T. IV, Madrid, Real Academia Española, 1926, p. 212-3. Los ejemplares de la edición de la Práctica de procuradores de Juan Muñoz contratados por Sebastián Sánchez con el impresor Francisco Sánchez el 9 de mayo de 1573 se entregaron el 14 de julio de ese año. Vid. PÉrez PASTOR, Bibliografía Madrileña ó descripción de las obras impresas en Madrid... Parte tercera (1621-1625), p. 434.

${ }^{17}$ Juan Díaz contrató al impresor Antonio de Nebrija para imprimir el Vocabulario de Nebrija el 11 de septiembre de 1570 debiendo imprimir un pliego diario. Vid. OBRA Sierra, Osorio Pérez, Moreno Trujillo, «El mercado del libro en Granada en el siglo XVI», p. 62.

18 En el contrato concertado entre El librero Alonso de arroyuelo y otros y Jorge Coci, impresor de Zaragoza, para imprimir un Brebiario para la diócesis de Burgos el impresor se obliga a entregar la edición en esa localidad. Vid. ABIZANDA Y BROTO, Documentos para la historia artística y literaria de Aragón procedentes del Archivo de Protocolos de Zaragoza, vol. 1, p. 321. También PeDrazA, Documentos para el estudio del libro en Zaragoza, 1501-1521, doc. 377.

${ }^{19} \mathrm{El} 30$ de agosto de 1602 fray Cristóbal Fonseca, autor y editor de sus Milagros de Cristo, que imprimieron Julio Junti y Juan Flamenco se vio obligado a pagar a los impresores 300 reales para adquirir baldreses y otros aparejos. Vid. Cristóbal PÉREZ PASTOR, Bibliografía Madrileña ó descripción de las obras impresas en Madrid... Parte segunda (1601-1620), Madrid, Tipografía de la "Revista de Archivos, Bibliotecas y Museos", 1906, p. 39. 
las personas que contratan, su responsabilidad en el pacto, las penas que se establecen por el incumplimiento del contrato, los avalistas en caso de incumplimiento... ${ }^{20}$

El maestro de la imprenta, a la vista del original (manuscrito o impreso) antes del contrato había establecido ya una aproximación bastante acertada al coste total de la impresión. La pericia y experiencia del maestro y la habilidad para establecer estos presupuestos hacían que el taller tuviera éxito o desapareciese, ya que la producción de libros era una actividad tremendamente competitiva. ${ }^{21}$ Por esta causa, también pueden encontrarse reflejados muchos aspectos técnicos que desde la perspectiva de la producción bibliográfica tienen especial interés porque van a determinar el grado de participación de cada uno de los contratantes en el producto final. Esta cuestión es trascendente porque si el grado de intervención del editor en los aspectos técnicos es muy profundo relega al impresor a una mera función de ejecutor de unas instrucciones sobre la estructura del libro que ha sido planificada de forma previa por el editor, que, no se puede olvidar, es también perfecto conocedor de los gustos de los lectores.

\section{El editor y su participación en la elaboración del libro}

Algunas de los cuestiones acordadas o impuestas por los editores podrían parecer en la actualidad de difícil comprensión. Entre ellas, la de que el editor se obligue a poner una imprenta, ${ }^{22}$ la de pagar el alquiler de la imprenta ${ }^{23}$ o la de obligar al impresor a montar imprenta. ${ }^{24}$

\footnotetext{
${ }^{20}$ Cuando una compañía de editores encabezada por Gabriel de Zayas contrata el 28 de enero de 1573 a Felipe de Junta para imprimir unos Diurnales ponen como avalista a Lucas de Junta. Vid. PÉREZ PASTOR, «Impresores y libreros de Madrid: documentos referentes a ellos», p. 202.

${ }^{21}$ Sobre los mecanismos de cómputo tipográfico pueden consultarse: Alonso VíCTOR DE PAREDES, Institución y origen del arte de la imprenta y reglas generales para componedores, ed. y pr. de Jaime Moll, nueva noticia editorial de Víctor Infantes, Madrid, Calambur, 2000, ff. 35 v.38; Juan José SigüEnZA Y VerA, Mecanismo del arte de la imprenta, Madrid, Imprenta de la Compañía, 1811, hay ed. facs. Madrid, J. Ollero - R. Ramos, 1992; pp. 17-33. Cf. Ronald B. McKerrow, Introducción a la bibliografía material, Madrid, Arco/Libros, 1998. Trad. de An Introduction to Bibliography for Literary Students, 2nd. ed. corr., Oxford, Oxford University Press, 1951, pp. 134-6.

${ }^{22}$ El 25 de enero de 1555, el cabildo de Oviedo y Agustín de Paz pactan la impresión de un Breviario de Oviedo, para lo que el Cabildo se obliga a poner imprenta. Vid. Jesús GONZÁLEZ CELADA, «Una misa propia dedicada a los SS.MM. Emeterio y Celedonio en un misal de 1556 en la Catedral de San Salvador de Oviedo», Kalakorikos, 15 (2010), pp. 389-401.

${ }^{23}$ Según el contrato de la Diputación del Reino de Aragón y Domingo de Portonariis para imprimir La historia del rey Don Hernando de Zurita el 28 de febrero de 1579, la institución se
} 
Entre los aspectos técnicos, quizás el que más podría destacarse, es el de la elección de los trabajadores que van a participar en la edición y la impresión. La selección del corrector es el más frecuente. Las imprentas no poseían correctores y normalmente esta función debía correr a cargo del maestro impresor, que seguramente miraría más por el rápido desarrollo del trabajo que por la correcta ejecución del mismo, lo que daría lugar a la desconfianza de los editores. Por esta causa estos imponían que esta función debía correr a cargo de una persona ajena a la imprenta. Especialmente cuando el editor es también el autor de la obra él mismo se dedica a la corrección de los pliegos impresos. ${ }^{25}$ También se pacta el número de pruebas que se han de corregir ${ }^{26}$ pudiendo exigir que fuesen firmadas por el corrector. ${ }^{27}$ Pero no solamente se exige que el corrector sea una persona determinada también se llega a acordar quiénes van a realizar las labores más técnicas en la imprenta: cajistas o tiradores, ${ }^{28}$ el número de cajistas por prensa $^{29}$ e, incluso lo que han de cobrar por su trabajo cajistas y prensistas (tiradores y batidores). ${ }^{30}$

obliga a pagar el alquiler de la imprenta. Vid. ABIZANDA y BROTO, Documentos para la bistoria artística y literaria de Aragón procedentes del Archivo de Protocolos de Zaragoza, vol. 1, pp. 347-50.

${ }^{24}$ En el contrato entre la Diputación del Reino de Aragón y Domingo de Portonariis para imprimir La tercera parte de los Anales de Aragón el 9 de abril de 1579. Vid. ABIZANDA Y BROTO, Documentos para la historia artística y literaria de Aragón procedentes del Archivo de Protocolos de Zaragoza, vol. 1, p. 351-3. También Publicado en Manuel José PEDRAZA GRACIA, «In Epilensi oppido: aportación documental sobre la primera imprenta de Épila en 1578», Gutenberg Jabrbuch, 1993, pp. 139-54; y en SAN VICENTE, Apuntes sobre libreros, impresores y libros localizados en Zaragoza entre 1454 y 1599, doc. 23.

${ }^{25}$ El 1 de agosto de 1528 Gaspar Lax y Pedro Hardouin contratan la impresión de unas obras de Lax. Vid. PeDrazA, Documentos para el estudio de la historia del libro en Zaragoza entre 1501 y 1521, p. 13, nota 40. Publicado posteriormente como primicia en Miguel Ángel Pallarés, Esperanza Velasco, La imprenta en Aragón, Zaragoza, Caja de Ahorros de la Inmaculada de Aragón, 2000.

${ }^{26}$ En el contrato firmado el día 27 de noviembre de 1586 la Diputación del Reino de Aragón y Domingo de Robles para la impresión de los Scholia ad Molinum de Jerónimo de Portolés se estipula que se harán tres pruebas. Vid. ABIZANDA Y BROTO, Documentos para la historia artística y literaria de Aragón procedentes del Arcbivo de Protocolos de Zaragoza, vol. 1, pp. 368-70.

${ }^{27}$ El 13 de julio de 1574 Juan Díaz pacta con el impresor Pierres Cosin, que las pruebas de la obra de Juan de Ávila que han pactado imprimir vayan firmadas por el corrector que es el propio Juan Díaz. Vid. PÉREZ PASTOR, Bibliografía Madrileña ó descripción de las obras impresas en Madrid... Parte tercera (1621-1625), pp. 330-1.

${ }^{28}$ Los editores de la Historia Pontifical pactan con el impresor Juan Soler que los cajistas sean Miguel Sánchez Godino y Jacques y que el tirador sea Tolosa. Vid. ABIZANDA Y BRoto, Documentos para la historia artística y literaria de Aragón procedentes del Archivo de Protocolos de Zaragoza, vol. 3, p. 225. Lo localiza en 1586. También, posteriormente, en SAN VICENTE, Apuntes sobre libreros, impresores y libros localizados en Zaragoza entre 1454 y 1599, vol. 2, doc. 45.

Titivillus, ISSN 2387-0915, ISSN-e 2603-9966, 1 (2015), pp. 211-226 
Si la elección de los responsables de la edición llega a pactarse y se estipulan por influencia del editor aspectos tan esenciales como los vistos hasta ahora, se puede empezar a vislumbrar que la participación de los editores puede llegar a incidir en aspectos técnicos mucho más específicos. Aunque la orientación económica del negocio es capital y así se refleja en la documentación, existe siempre un mayor interés en determinados aspectos técnicos y de contenido que devienen en fundamentales cuando los autores asumen la edición de sus propias obras, mientras que la función propagandística es la que tiene mayor importancia en los contratos en los que los editores son las instituciones de todo tipo.

En general, se buscaba un referente que sirviese de guía para la impresión de la nueva edición o de la nueva obra que solía ser una edición previa; 31 pero, si era preciso, se elaboraban hojas de muestra sobre las que se cerraba la impresión. ${ }^{32}$

... Conforme al original que le entregara el doctor Ramellone, tan bien impreso y con letras nuevas de las mismas diferencias de formas que esta el "Manual" impreso en Madrid por Tomas de Juncta año de mil y quinientos noventa y cinco, de colorado y negro como esta el dicho "Manual", con sus cotas marginales como se daran en el original. ${ }^{33}$

\footnotetext{
29 Jerónimo Serra contrata al impresor Gabriel de Hijar (Dixar) para imprimir Los ocho libros de la Monarchia eclesiástica de fray Juan de pineda en 1576 estipulando que se emplee un cajista por cada prensa. Vid. Manuel José PEDRAZA GraCIA, La imprenta de Gabriel de Hijar (Zaragoza, 1576), Zaragoza, Institución "Fernando el Católico", 1991, doc. 17, pp. 128-30. Resume: ABIZANDA Y BROTO, Documentos para la historia artística y literaria de Aragón procedentes del Archivo de Protocolos de Zaragoza.
}

30 Domingo de Portonariis es contratado por Melchor Sotes para imprimir El caballero del Febo el 23 de abril de 1579, acordando que el editor pagará a los cajistas 124 reales mensuales y 94 a los trabajadores de la prensa. Vid. SAN VICENTE, Apuntes sobre libreros, impresores y libros localizados en Zaragoza entre 1454 y 1599, vol. 2 doc. 34.

31 El 8 de enero de 1535 Lope Ruiz de Contreras contrata a Jorge Coci para imprimir Misales para el obispado de Urgel tomando como referencia el Misal que había impreso para el obispado de Tarazona. Inédito. Inédito. A.H.P.N.Z., Protocolo de Juan Arruego 1535, cuaderno numerado con el f. 19.

32 Manuel José Pedraza GRACIA, «Las muestras en las capitulaciones para la impresión de libros: análisis de dos muestras del siglo XVI», Pliegos de bibliofilia, 13 (2001), pp. 33-42; Víctor INFANTES DE MIGUEL, «La "muestra de impresión": un testimonio inédito de la estrategia editorial del Siglo de Oro», en Anne Cayuella, Roger Chartier (coords.), Edición y literatura en España (siglos XVI y XVII), Zaragoza, Prensas Universitarias de Zaragoza, 2012, pp. 137-68.

${ }^{33}$ La muestra en este caso no fue añadida al documento o, posiblemente, se hava perdido. $V i d$. SAN VICENTE, Apuntes sobre libreros, impresores y libros localizados en Zaragoza entre 1454 y 1599, nota 46, vol. 2, doc. 95.

Titivillus, ISSN 2387-0915, ISSN-e 2603-9966, 1 (2015), pp. 211-226 
Estas muestras son una de las fuentes más interesantes para calibrar la intervención del editor en la concepción estética de la mancha de escritura, su distribución y el resto de los elementos estructurales de la página ya que se aprecia a la perfección la oferta realizada por el impresor y las correcciones que sobre ella efectúa el editor.

Entre los principales gastos de la impresión de in libro se encuentra el del papel, que era un producto caro. No extraña, por consiguiente, que todo lo que se refiere al papel sea uno de los aspectos que más claramente se definen en los contratos. De hecho, como ya se ha visto, las unidades de papel son casi siempre las que determinan el coste de la edición. Lo principal era estipular quien adquiere el papel para la impresión, aunque casi siempre es el editor el que lo hace o encarga que el papel proceda de un determinado lugar ${ }^{34}$ y de un tipo específico, ${ }^{35}$ en ocasiones se ocupa de su adquisición el impresor. ${ }^{36} \mathrm{La}$ existencia de algunas emisiones relacionadas con el uso de soportes diferentes queda reflejada en el contrato. ${ }^{37}$ Este aspecto, es sin embargo, muy difícil de apreciar en los ejemplares conservados salvo que se proceda a su comparación sistemática o la emisión sea evidente (papel y pergamino, por ejemplo).

También se pacta la calidad de la tinta ${ }^{38}$ y el uso de tintas rojas (que en algún documento se denominan rubias). ${ }^{39} \mathrm{Y}$, por supuesto, la calidad, ${ }^{40}$ la

34 El 29 de mayo de 1576 Fernando de Cabezón contrata con Francisco Sánchez la impresión del Libro de tecla y vibuela de Antonio de Cabezón que se imprimirá en papel de Génova de la marca B. f. Vid. Cristóbal PÉrez PASTOR, «Escrituras de concierto para imprimir libros», Revista de Archivos, Bibliotecas y Museos, año I, 8/9 (1897), pp. 364-8.

35 El 3 de marzo de 1575 fray Juan del Espinar contrata al impresor Juan de la Plaza para imprimir unos Calendarios perpetuos en papel del romero o del corazón. Vid. PÉREz PASTOR, «Impresores y libreros de Madrid: documentos referentes a ellos», p. 212-3.

${ }^{36}$ En 1528 Gaspar Lax contrata con Pedro Hardouin, que se ocupa de adquirir el papel, la impresión de sus obras. Vid. nota 35.

37 Francisco López contrató a Julio Junti de Modesti el 3 de noviembre de 1600 para imprimir las Historias generales de las Yndias de Antonio de Herrera en el contrato se estipula la elaboración de 60 ejemplares en papel marquilla para el Consejo de Indias de los cuales 6 deben estar, además, dorados. Vid. Mercedes AgulLó y COBO, La imprenta y el comercio de libros en Madrid: (siglos XVI-XVIII). Documentos generales, Madrid: Universidad Complutense de Madrid, Servicio de Publicaciones, 2009, pp. 276-8.

${ }^{38}$ El 3 de noviembre de 1600 Francisco López contrata a Julián Junti de Modesti para imprimir las Historias generales de la Yndias de Antonio de Herrera con buena tinta y de aceite de linaza. Vid. Agulló, La imprenta y el comercio de libros en Madrid: (siglos XVI - XVIII). Documentos generales, pp. 276-8.

${ }^{39}$ El Obispo de Palencia contrata a Francisco y Mateo de Canto para imprimir los Manuales del arzobispado con tinta negra y rubia. Vid. PÉrez PASTOR, La imprenta en Medina del Campo, pp. 124-5. 
tipografía ${ }^{41}$ y las ilustraciones. Las letras se seleccionaban mediante catálogos o muestras elaboradas por el impresor ${ }^{42}$ o por comparación con otras obras impresas. Los tacos xilográficos y planchas metálicas, por ser productos de cierto precio, no siempre pertenecían al impresor o eran costeadas por él. ${ }^{43}$ De hecho, los preliminares gráficos casi siempre hacen referencia al editor y parece lógico que esas ilustraciones parlantes sean propiedad de los editores más que de los impresores. ${ }^{44}$ Por esta causa se pueden encontrar contratos en los que se especifica sin lugar a dudas la posición en la que deben ir esas ilustraciones, que suele ser la portada. ${ }^{45}$ En algún caso conocido son tan concretas las especificaciones sobre las ilustraciones y su disposición que el editor deja la portada perfectamente diseñada en el contrato.

Ittem que en el principio de cada bolumen se hayan de poner las armas del Reyno las mismas que en la $2^{a}$ y $3^{a}$ parte poniendo el titulo de cada bolumen encima d'ellas asi devaxo parecera poner la divisa del rio Ebro se avisara con tiempo y tambien para si sera nesçesario que se corten otras armas porque las que ay de las impresiones pasadas estan algo gastadas. ${ }^{46}$

40 En la impresión del libro de Antonio de Cabezón ya citado se exige que se fundieran de nuevo la letra y otros signos. Vid. PÉREZ PASTOR, «Escrituras de concierto para imprimir libros», pp. 364-8.

${ }^{41}$ Generalmente se especifica que la letra sea atanasia pero figuran otras muchas: sumas, paladina o antigua romana, texto de París como la de Plantino, cícero, peticanon, ciceroniana...

42 Juan de Moros contrata a Jorge Coci para imprimir un Breviario de Solsona en 1514. En el contrato se pacta la selección de letras de entre las muestras que proporciona el impresor. Vid. Pedraza, Documentos para el estudio de la historia del libro en Zaragoza entre 1501 y 1521, doc. 979.

43 El 25 de enero de 1555 el cabildo de Oviedo contrata a Agustín de Paz para que imprima un Breviario de la diócesis en el que costea la ilustración. Jesús GONZÁLEZ CELADA, «Una misa propia dedicada a los SS.MM. Emeterio y Celedonio en un misal de 1556 en la Catedral de San Salvador de Oviedo», Kalakorikos, 15 (2010), pp. 389-401.

${ }^{44}$ Como ocurre con los ya mencionados Manuales de Palencia, en los que se indica que al principio deben ir las armas, insignias y títulos del Obispo. Vid. PÉrez PAstor, La imprenta en Medina del Campo, pp. 124-5.

45 Así se acuerda en el contrato de impresión del Libro de tecla y vibuela, mencionado con anterioridad. Vid. PÉREZ PASTOR, «Impresores y libreros de Madrid: documentos referentes a ellos», p. 216.

46 El mismo acto se encuentra en el Archivo de Protocolos de Zaragoza (Protocolo de Jerónimo Andrés 1584, ff. 1.680 / 1.682 v.) y entre los actos comunes del Archivo de la Diputación del Reino de Aragón (Actos comunes 1584, cuaderno intercalado de 11 f.). Publicado en Ángel Canellas LópeZ, «Los Anales de la Corona de Aragón de Jerónimo Zurita», en VII Congreso de Historia de la Corona de Aragón, Barcelona, 1962, pp. 78-80, que menciona como fecha del contrato el mes de noviembre; en Diego NAVARRo BONILLA, «Noticias históricas en torno a la segunda edición de la primera parte de los Anales de 
Además de las materias primas, imprescindibles para la elaboración del libro, otros aspectos que configuran la estructura material del libro estaban perfectamente concretados como el formato ${ }^{47}$ y el número de cuadernos por cuerpo. ${ }^{48}$ Estos parámetros de la edición responderían a un perfecto cómputo tipográfico realizado por el impresor previamente. Por lo que serían datos aportados por él al contrato, pero a los que el editor quiere que se atenga a fin de evitar incrementos de gasto. Además, hay aspectos esenciales de la compaginación como el número de líneas por página, ${ }^{49}$ la composición en columnas, ${ }^{50}$ márgenes, ${ }^{51}$ marginalia ${ }^{52}$ que también se acuerdan...

Zurita (Juan bautista de Negro-Simón de Portonariis, 1585», Jerónimo Zurita, 74 (1999), pp. 101-31, que menciona como folios 2.680 / 2.682 v.; y en SAN VICENTE, Apuntes sobre libreros, impresores y libros localizados en Zaragoza entre 1454 y 1599, nota 46, vol. 2, doc. 58. Cf. Manuel José Pedraza Gracia, «Poder político e imprenta en el Renacimiento en la Península Ibérica: el libro y la Diputación del Reino de Aragón en los siglos XV y XVI», Cuadernos para Investigación de la Literatura Hispánica, 29 (2004), pp. 295-320; pp. 315-6.

${ }^{47}$ El 3 de noviembre de 1575 fray Juan del Espinar contrata con el impresor Juan de la Plaza la impresión de Breviarios en dos formatos $8^{\circ}$ y $16^{\circ}$. Vid. PÉREZ PASTOR, «Impresores y libreros de Madrid: documentos referentes a ellos», p. 211.

${ }^{48}$ El librero Juan López contrata el 14 de febrero de 1567 al impresor Juan de Villanueva para imprimir el Arte de amar a Dios en el que se acuerda que cada cuerpo tendrá 20 pliegos. Vid. Agulló, La imprenta y el comercio de libros en Madrid: (siglos XVI - XVIII). Documentos generales, p. 335. Lo mismo se fija, veinte pliegos por cuerpo, en el contrato de edición del Libro de tecla y vibuela de Cabezón, ya citado. Vid. PÉrEZ PASTOR, «Escrituras de concierto para imprimir libros», pp. 364-8.

${ }^{49}$ El 20 de noviembre de 1574 Francisco López pacta con el impresor Francisco Sánchez, edición de los Dialogo de la verdadera honra militar en el que se compondrán 29 renglones con título y reclamo por plana. Vid. PÉREZ PASTOR, Bibliografía Madrileña ó descripción de las obras impresas en Madrid... Parte tercera (1621-1625), p. 488

${ }^{50}$ En 1603 Francisco Lozano contrata a Miguel Serrano de Vargas para imprimir un Flos Sanctorum. En el contrato se determina que las páginas tendrán dos columnas y 49 renglones por columna. Vid. AGULLÓ, La imprenta y el comercio de libros en Madrid: (siglos XVI - XVIII). Documentos generales, pp. 688-9.

${ }^{51}$ En el contrato de la edición de los Manuales del Obispado de Palencia, pactado en 1553, se concreta que los márgenes de las páginas serán iguales al Manual de Salamanca. Vid. PÉREZ PASTOR, La imprenta en Medina del Campo, pp. 124-5.

52 Francisco López contrata el 20 de noviembre de 1574 a Francisco Sánchez para imprimir el Dialogo de la verdadera honra militar, en el que se acuerda que posee apostillas militares. Vid. PÉREZ PASTOR, Bibliografia Madrileña ó descripción de las obras impresas en Madrid... Parte tercera (1621-1625), p. 488. 
El editor, debido a la desconfianza existente en estos negocios comerciales, determina una salvaguarda con objeto de evitar que el impresor pueda producir más libros de los estipulados, escamotearlos a la hora del control que ejerce el editor y venderlos por su cuenta. Aunque esta salvaguarda podía dar lugar a acuerdos que se plasmaban en otros tipos documentales, los métodos de control de ejemplares más exigentes consistían en que el editor firmase los ejemplares ${ }^{53}$ o que los pliegos impresos se

entregasen al editor. ${ }^{54}$ En el primero de los casos bastaba con que se firmase un pliego, normalmente el primero, y contabilizar el número de firmas realizadas. Éste debía

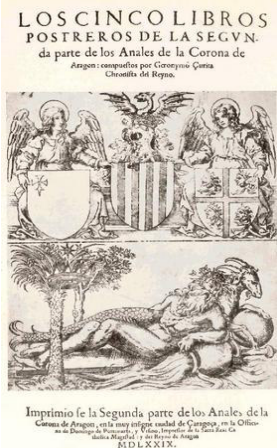

Il. 1: Zurita, Jerónimo, Los cinco libros postreros de la segunda parte de los Anales de la Corona de Aragón. Zaragoza, Domingo de Portonariis y Ursino, 1579. Portada coincidir con el número de ejemplares establecido contractualmente. Una vez concluida la publicación, era suficiente comprobar que en todos ellos figuraba la firma del editor. El mayor grado de intervención de un editor (independientemente de que además tenga otras responsabilidades en la obra, como la autoría) lleva a acoger en su casa las herramientas de impresión con objeto de que el control sobre la fabricación sea total.

Mas es tractado que el dicho Lorenzo de Robres ha de traher un prensa y lo necesario para imprimir dicha obra a la casa del dicho Jeronimo Martel y solo se le ha de dar, y el dicho Jeronimmo Martel se obliga darle, todo el el paper que fuere menester para dicha impresion de dichos cuerpos de libros junto a la dicha prensa. Y todo lo demas que fuere menester para dicha impresion a de poner, y se obliga a ponerlo, el dicho Lorenzo de Robres lo que fuere necesario para dicha impresión. ${ }^{55}$

\footnotetext{
${ }^{53}$ Melchor Sotes el 8 de mayo de 1580 contrata con Domingo de Portonariis la impresión del Flos Sanctorum de Villegas. En el contrato se estipula que los ejemplares deben ir firmados por manos de Sotes. Vid. SAN VICENTE, Apuntes sobre libreros, impresores y libros localizados en Zaragoza entre 1454 y 1599, vol. 2, doc. 42.

${ }^{54}$ El librero de Madrid Antonio Manuel contrata a María Ruiz, viuda del impresor Alonso Gómez, el 11 de julio de 1588 para imprimir las Meditaciones soliloquio y manual. En el contrato se pacta que el editor debe recibir medio pliego impreso todos los días. Vid. PÉREZ PASTOR, Bibliografía Madrileña ó descripción de las obras impresas en Madrid.. Parte tercera (1621-1625), p. 323.

55 El infanzón zaragozano Jerónimo Martel y el impresor Lorenzo de Robles el 25 de septiembre de 1594 contratan la impresión de 750 ejemplares de la Chronologia universal. Vid. SAN VICENTE, Apuntes sobre libreros, impresores y libros localizados en Zaragoza entre 1454 y 1599, nota 46 , vol. 2 , doc. 88 .
} 
Habrá que esperara al siglo XVIII para que la encuadernación sea otro de los aspectos pactados dando lugar a encuadernaciones editoriales. ${ }^{56}$ Pero en los contratos se encuentran también referencias a la distribución de la edición, bien sea porque se intenta excluir un ámbito comercial específico ${ }^{57}$ o porque el editor pretenda evitar la competencia del impresor en la venta de la parte de la edición que le corresponde. ${ }^{58}$

\section{A modo de conclusión}

La función principal del editor es, por supuesto, tomar la iniciativa sobre la publicación de una obra o de la nueva edición de una obra ya conocida. Por esto, se puede determinar que sería este el aspecto que diferencia y define al editor con respecto a cualquier otro participante en la creación del libro. Muchas veces esa función es asumida por diversos actores de la creación, producción y distribución del libro; pero no siempre.

Además, el editor puede, a través del contrato de edición, asumir una serie de actividades que definirán y darán forma al producto final, el libro. Estas actividades se desarrollan en todos los procesos de la producción del mismo: la selección del papel, de la tipografía, de las ilustraciones, el diseño de la página. Este proceder es consecuencia de que el editor persigue aportar a la edición su concepción sobre el libro, especialmente por lo que se refiere al ámbito de la percepción estética de la página o del conjunto. Por esta causa, llega a definir la estructura de la portada o a imponer la inclusión de prólogos que ensalcen su figura o actividades.

El editor puede llegar en estas actuaciones hasta el extremo de tomar bajo su control económico todos los elementos de la imprenta que intervienen en la impresión, materiales y personales disponiendo una ubicación concreta para las prensas, la elaboración de recursos tipográficos específicos, la elección de los encargados de la corrección o de los cajistas y de los tiradores.

Es, por tanto, momento de que la investigación se preocupe y ocupe más en estudiar y en discernir cuáles son las intervenciones de los editores en la

\footnotetext{
56 Manuel Rodrigo acuerda con el impresor Juan José Ezquerro en 1713 la edición del Libro de medicina de tratado de baños, en el que se acuerda también la encuadernación. Vid. Javier ITÚRBIDE DíAZ, Escribir e imprimir: el libro en el Reino de Navarra en el siglo XVIII, Pamplona, Institución Príncipe de Viana, 2007, Apéndice documental, doc. 4. En 1740 Francisco Toledano acuerda la impresión y encuadernación de la Historia de la ciudad de Lorca con el impresor Francisco José López. Vid. PÉREZ PASTOR, «Escrituras de concierto para imprimir libros», pp. 363-71.

57 Vid. PÉrez PASTOR, Bibliografía Madrileña ó descripción de las obras impresas en Madrid... Parte tercera (1621-1625), p. 460.

${ }^{58}$ Como ocurre con la distribución de los ya mencionados Misales de Lérida contratados en 1524 impresos por Jorge Coci que debe esperar, según el pacto contractual, un año hasta poder vender la parte que le toca de la edición.
}

Titivillus, ISSN 2387-0915, ISSN-e 2603-9966, 1 (2015), pp. 211-226 
producción bibliográfica del pasado, dando a esta figura la relevancia que realmente posee. 